\title{
UNA DISCUSIÓN SOBRE EL SIGNO FORMAL (1)
}

\section{A DISCUSSION ON FORMAL SIGN (1)}

\author{
Pbro. Dr. Diego José Bacigalupe
}

\section{Resumen}

En este artículo, discutimos la teoría del signo formal de Juan de Santo Tomás. En primer lugar, mostraremos algunas objeciones que M.-D. RolandGosselin hizo a esta teoría. En segundo lugar, intentaremos responderlas, pero modificando algunos puntos de la elaboración de Juan de Santo Tomás. Una evaluación de la tesis en su integridad quedará para un próximo artículo.

\section{Abstract}

In this article, we discuss John Poinsot's theory of formal sign. First, we show some objections that M.-D. Roland-Gosselin has made to this theory. Second, we answer them, but modifying some points of Poinsot's statements. We leave an evaluation of the whole thesis for a next article.

Todo estudiante de filosofía, una vez puesto delante de los contenidos de antropología o gnoseología, tiende a hacerse ciertas preguntas respecto del conocimiento: ¿cómo es posible que algo dentro de mí se refiera a algo exterior a mí, difiriendo en tanto que algo en mí es universal y fuera de mí, particular? ¿Y cómo puede explicarse que algo distinto de mí de alguna manera esté en mí? ¿Cómo explicar, además, que eso dentro de mí sea conocido con posterioridad a la cosa a la cual se refiere? ¿Y cómo evitar decir que, conocida la cosa, es menester que fuera conocido su representante interior? ¿Cómo sostener la existencia de conceptos y al mismo tiempo no hacerlos pasar por objetos conocidos? ¿Y cómo, en última instancia, resolver la tendencia cartesiana de considerar una intencionalidad de dos pasos, es decir, de conocer la cosa-en-mí para después conocer la cosa-en-sí? Preguntas de esta especie surgen cuando 
estudiamos estos temas, preguntas tales que pueden acompañarnos muchos años.

En mi caso, un ensayo de J. Maritain titulado Signo y símbolo incluido en los Cuatro ensayos sobre el espíritu en su condición carnal (1988) -que me hiciera conocer convenientemente Mons. Héctor Aguer-, me iluminó con una noción que, aunque antigua en sí, resultó novedosa para mí: Maritain trataba allí al concepto como un signo formal. En las abundantes notas del texto había una referencia casi exclusiva a Juan de Santo Tomás.

La teoría, en líneas generales, afirma que las características propias del signo se dan en el concepto. Ellas se reducen, fundamentalmente, a ser dos entidades distintas de las cuales una se refiere a otra. Así, cuando juzgo que el tren está por llegar, los conceptos en juego -y el juicio también- hacen presente una realidad que no son ellos mismos. Sin embargo, es un hecho que los signos, en general, son conocidos antes que sus referentes. Así, una señal de tránsito, como un paso a nivel, me indica algo que está por venir. En esto, el concepto difiere de los signos en general, puesto que no es conocido antes que las cosas, sino que, haciendo presente algo distinto de sí, él mismo no aparece a la consideración explícita de la inteligencia. Por esta razón es que se lo llama signo formal, distinguiéndolo de los signos instrumentales, en los que el signo ut res aparece a la consideración de los sentidos o de la inteligencia con anterioridad lógica al significado.

La solución a las preguntas con las que abrimos este estudio parece dada por esta teoría, pero basta hurgar un poco en la bibliografía para empezar a comprender que, al menos, no es una solución pacífica. Particularmente una recensión de Roland-Gosselin a las Réflexions sur l'intelligence de Maritain (1984) nos puede hacer entender que no es tan evidente para todos que el concepto sea, efectivamente, un signo. El texto dice así:

Por reacción contra la teoría, atribuida a Vázquez y a Descartes, del 'concepto objetivo' (donde él ve el germen del idealismo), Maritain tiende manifiestamente a disimular o a reducir (no digo: a suprimir) el rol jugado en el conocimiento intelectual por la semejanza del concepto con la realidad. Y, para alcanzar esto, él usa simultáneamente dos medios: 1) En primer lugar, afirma en términos absolutos (demasiado absolutos a mi arbitrio) la identidad de la esencia considerada bajo su modo de existencia real y de la esencia considerada bajo su modo de ser intencional en el concepto o verbo mental. 2) Después, él ve en el concepto, siguiendo a Juan de Santo Tomás, un puro signo formal, es decir, un signo que hace conocer lo que significa sin ser primero él mismo conocido. Hasta donde conozco, ni uno ni el otro de estos principios de solución, en el sentido preciso que los toma Maritain, puede apelar a la autoridad de santo Tomás de Aquino. Pero, en todo caso, me parece imposible quererlos fundir en uno solo. Si, en efecto, el concepto, el verbo mental, es puro 
signo inconsciente de la esencia que hace conocer, ¿cómo identificarlo con la esencia de la cosa conocida? (Roland-Gosselin, 1925, págs. 201-202) ${ }^{1}$.

Dado que el concepto es una semejanza de la cosa conocida (con matices distintos, esto lo sostienen los dos autores), la objeción se articula en cuatro planos:

1. Maritain reduce la semejanza a la identidad.

2. Maritain reduce la semejanza a la significación.

3. Las afirmaciones de Maritain no tienen sustento en la obra de Santo Tomás de Aquino.

4. Las afirmaciones de Maritain no tienen sustento en la realidad.

Los cuatro planos de la objeción generan, ampliando el problema, los siguientes cuatro interrogantes:

1. El concepto, ¿es semejante o idéntico a lo conocido?

2. Siendo semejante o idéntico a lo conocido, el concepto, ¿puede ser llamado signo?

3. Una teoría como la del signo formal, ¿tiene sustento en los textos de santo Tomás?

4. Una teoría como la del signo formal, ¿tiene sustento en la realidad?

Estos interrogantes articularán, pues, la presente investigación.

\section{Qué es el concepto}

Las preguntas planteadas suponen una mínima noción acerca de qué sea el concepto. Con la palabra 'concepto' nos referimos al fruto de la primera operación intelectual, esto es, de la simple aprehensión. Se trata de la captación inmediata de la esencia o alguna nota esencial de algo. Es llamado 'palabra de la mente' (verbum mentis), aunque bajo esta denominación englobamos al fruto de las dos primeras operaciones intelectuales, no sólo de la simple aprehensión, sino también del juicio (cf. Tomás de Aquino, Super Evangelium s. Ioannis

\footnotetext{
${ }^{1}$ En las traducciones nuestras, ofrecemos el original a pie de página: "Par réaction contre la théorie, attribuée à Vasquez et à Descartes, du " concept objectif », et où il voit le germe de l'idéalisme, M. [Maritain] tend manifestement à dissimuler ou à réduire (je ne dis pas: à supprimer) le rôle joué dans la connaissance intellectuelle par la ressemblance du concept avec la réalité. Et, pour y parvenir, il use simultanément de deux moyens: 1) Tout d'abord il affirme en termes absolus (trop absolus à mon gré) l'identité de l'essence considérée sous son mode d'existence réelle et de l'essence considéré sous son mode d'être intentionnel dans le concept ou verbe mental. 2) Puis il voit dans le concept, à la suite de Jean de Saint-Thomas, un pur signe formel, c'est-à-dire un signe qui fait connaître ce qu'il signifie sans être d'abord lui-même connu. A ma connaissance ni l'un ni l'autre de ces principes de solution, au sens précis où les prend $\mathrm{M}$., ne peut se réclamer de l'autorité de saint Thomas d'Aquin. Mais en toute hypothèse il me paraît impossible de les vouloir fondre en un seul. Si, en effet, le concept, le verbe mental est pur signe inconscient de l'essence qu'il fait connaître, comment l'identifier avec l'essence de la chose connue?" Para un análisis de la discusión entre ambos autores, cf. (Bacigalupe, 2014, págs. 371397).
} 
lectura, 1972, I, I.1, 25). Ambas operaciones están relacionadas: el concepto es para el juicio, ya que la inteligencia reposa en la verdad que se da en esta operación, y el juicio incluye materialmente a los conceptos, ya que está hecho de ellos. De allí que, aunque la objeción de Roland-Gosselin recaiga sobre los conceptos, la pregunta sobre todo signo formal incluye también al juicio.

En todo caso, previa abstracción, el intelecto en potencia pasa al acto de entender. Ahora bien, para que pueda pasar al acto de entender es necesario un principio formal que permita tal actualización. La vista, sin objetos coloreados visibles en acto (esto es, que estén bajo el influjo de la luz) que de algún modo la determinen formalmente, no puede pasar al acto de ver. No veo cualquier cosa, sino ciertos objetos visibles que determinan mi potencia visiva y me hacen ver. Así tampoco el intelecto paciente puede entender en acto sin una forma que lo determine y lo haga entender esto (concepto) o esto es así (juicio).

¿Qué forma puede determinar al intelecto paciente, en sí inmaterial? Evidentemente, la forma tiene que, por un lado, ser adecuada al intelecto y, por otro, ser la forma de algo inteligible. Es más, la forma es por lo que algo es inteligible y por lo cual algo es lo que es, en toda su riqueza. De donde, que aún el aspecto sensible incluye la presencia de esa forma, pero todavía no adecuada a nuestro intelecto. Una vez abstraída, vuelta inmaterial al modo del intelecto y por esta razón despojada de la materialidad individual que aún subsiste en los sentidos, la forma puede informar, determinar, al intelecto paciente y hacerlo pasar al acto de entender esto o esto es así.

La forma sustancial está presente, entonces, tanto en la cosa conocida como en el intelecto, pero no de la misma manera. En el primer caso, se encuentra in esse naturae, esto es, en su ser natural. Compete a las formas de las cosas materiales estar presente en la materia. No es lógico pensarlas separadas. Pero es que, justamente, sólo están separadas cuando las pensamos, jamás fuera del intelecto. Ahora bien, ¿cómo se encuentran en el intelecto? Las expresiones pueden ser variadas: in esse intentionali, in esse intentionis, in esse intelligibili.

Las primeras dos expresiones señalan dos aspectos importantes. En primer lugar, se contraponen al esse naturae, es decir, expresan que la forma se encuentra 'fuera del lugar que le es propio'. Así como la virtud del carpintero, que in esse naturae reside en este hombre, se transmite circunstancialmente a sus herramientas cuando las usa y se dice que esa misma virtud está en ellas in esse intentionali o in esse intentionis, así la forma sustancial se dice in esse intentionali o in esse intentionis cuando se encuentra en el intelecto (cf. Tomás de Aquino, Quaestiones disputatae de Potentia, 1965, q.3, a.7, ad7m.). En segundo lugar, estas dos primeras expresiones hacen referencia también a un origen, es decir, al lugar donde está la fuente de la cual brota toda la fuerza y la misma inteligibilidad de la forma en el intelecto. Así como la virtud del carpintero en la herramienta señala todo el tiempo al arte de este hombre como 


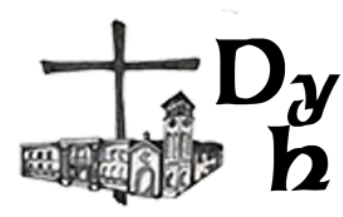

a su origen, así la forma en el intelecto señala todo el tiempo a la cosa inteligible como al lugar de donde brota toda su fuerza inteligible. Cf. (Hayen, 1939, pág. 387).

La tercera expresión (in esse intelligibili) denota en cambio la adecuación al intelecto paciente. El intelecto paciente es, en su ser natural, perfecto por ser inmaterial. Pero en el orden de la operación está en potencia. Sólo en el ser inteligible está en potencia, no porque él mismo no sea inteligible, sino porque, en el orden del ejercicio, puede alcanzar una perfección que de por sí no posee [cf. (Tomás de Aquino, 1996, a.16, ad 8m.)]. El ser inteligible es la expansión del acto de ser original del cognoscente en el orden de la operación.

Las tres expresiones, entonces, señalan la doble adecuación de la forma en la mente. Esa misma forma es tanto la forma de la cosa in esse naturae y la forma del intelecto in esse intelligibili. En este segundo caso se la llama 'especie inteligible'. A este respecto, conviene retomar un texto de santo Tomás:

Es conveniente que esta especie que es inteligida en acto perfeccione al intelecto en potencia, de cuya conjunción se hace algo uno perfecto que es el intelecto en acto, como desde el alma y el cuerpo se hace algo uno, que es el hombre que tiene operaciones humanas (Tomás de Aquino, Scriptum super libros Sententiarum, 1929-1947, I, d. 35, q. 1, a. 1, ad3m.) ${ }^{2}$.

La idea presente en el texto es que la conjunción de materia y forma, en el caso de la sustancia material, y del intelecto y la especie es análoga. ¿Qué es lo relativamente igual en ambos casos? Se trata de la conformación de un uno perfecto, esto es, de una sola cosa que tiene distintos principios. En la sustancia material no hay dos cosas, sino principios: "la materia última y la forma son uno y lo mismo, aquello en potencia y esto en acto" (Aristóteles, Metafísica, 2000, 1045b 18-19). Así, en el acto de entender, el intelecto paciente funge de materia y la forma sustancial de la cosa funge de forma del intelecto. Mientras que la unión de materia y forma se da como una sustancia in esse naturae, la unión del intelecto y la especie se da como un acto in esse intelligibili.

En pocas palabras, las sustancias pertenecen al orden de ser entitativo y los actos, al del ser operativo [cf. (Contat, 2012)]. No es el mismo orden, y de allí la desigualdad esencial. La relativa igualdad nos habla de la radical unidad que tiene una sustancia y también un acto, y también del hecho de tener principios constitutivos. Así, el acto de entender no es un proceso con distintos actos, sino un único acto, la determinación del intelecto posible por la forma abstraída para entender la cosa. Cf. (Llano, 1999, pág. 283).

Otra parte de la analogía que nos sirve en este momento es la siguiente: así como de la unión del cuerpo y el alma se sigue el hombre que tiene

\footnotetext{
2 "[...] oportet quod haec species, quae est intellecta in actu, perficiat intellectum in potentia: ex quorum conjunctione, efficitur unum perfectum quod est intellectus in actu, sicut ex anima et corpore efficitur unum, quod est homo habens operationes humanas".
} 
operaciones humanas, ¿habrá algo que se siga de la unión entre el intelecto paciente y la especie inteligible? De la plenitud de un acto algo tiende a seguirse. Del fuego en acto se sigue el calor en acto. $Y$ del intelecto en acto se sigue la 'palabra del corazón', el verbum mentis, donde el intelecto dice para sí mismo lo entendido. No lo dice al modo de una palabra en una lengua conocida, sino que se trata de la expresión puramente intelectual (acompañada, cuando es posible, de la imaginación) de lo entendido, de la dicción de esto o esto es así en el interior del hombre que entiende. El concepto (o el juicio) es un acto que procede de un acto. Él mismo es la riqueza del acto de entender manifestada al intelecto que entiende. $Y$ es también lo que manifestamos en palabras a nuestro exterior en la comunicación interpersonal, que continúa siendo -cuando se trata de una verdad que hemos adquirido- una expansión de la riqueza de nuestro entender.

Como es evidente, los conceptos no son estables en el intelecto, puesto que, entendiendo otra cosa, desaparece el concepto anterior. Las especies abstraídas, en cambio, permanecen de manera habitual para ser puestas a disposición de la inteligencia cuando sea necesario, generando otra vez el concepto. Ahora bien, si queremos establecer la categoría a la cual pertenece el concepto, deberemos incluirlo en la de cualidad [cf. (Delly, 2008, pág. 339); (Osborne, 2010, pág. 3)]. Sin embargo, nos atrevemos a decir que esto es así materialmente hablando. Formalmente hablando, al concepto le conviene más la denominación de acto que cualquier otra denominación, puesto que se encuentra en el orden operativo, no en el entitativo.

\section{Si el concepto es idéntico o semejante a lo conocido}

Habiendo dilucidado mínimamente la naturaleza del concepto, podemos responder la primera pregunta planteada. Semejanza e identidad son dos nociones relativas que se pueden prestar a confusión. De hecho, en el lenguaje corriente, la palabra 'semejanza' parece referirse a cosas 'que se parecen', mientras que 'identidad' nos habla de 'lo exactamente igual' sólo a sí misma, pero puede ser semejante a otras si comparte una cualidad. La cualidad, al mismo tiempo, se puede entender como un accidente o, por extensión, como la diferencia específica (o, en su lugar, los accidentes propios) que hace que una cosa sea formalmente diversa de otra (Tomás de Aquino, Summa Theologiae, 1888-1906, I, q.77, a.1, ad 7m. y I-II, q.49, a.2, c.). Así pues, dos caballos podrán ser semejantes por ser ambos blancos, y también así se dirán semejantes a un conejo blanco. Pero, en cuanto a la diferencia específica, los dos caballos serán semejantes entre sí, y desemejantes al conejo.

¿Cómo entra la cuestión de la 'semejanza' y la 'identidad' en el caso del concepto y la cosa conocida? Entre las características de la especie inteligible se encuentra la de ser 'una semejanza de la cosa conocida'. Esto denota el hecho 
de que la especie y la forma sustancial son, en realidad, una -según la cualidad-. Son, de hecho, la misma forma pero según un modo de ser distinto: in esse naturae en la cosa, in esse intentionali (o intelligibili, según qué aspecto se subraye) en el intelecto. Lo mismo cabe decir de las formas accidentales inteligidas.

Así pues, la especie y la cosa son semejantes. Es más, esta referencia es engañosa: la especie es toda ella una semejanza. No se compara la cosa conocida con la especie como se compara un caballo y otro caballo. Los caballos son semejantes entre sí. La especie no se dice semejante a la cosa. Lo que es semejante a la cosa, salvando las distancias, es el acto de entender formalizado por esta especie que es una semejanza de la cosa conocida. Así como la diferencia específica es lo que hace uno a dos caballos, así la especie es lo que hace uno al intelecto y la cosa conocida: "el intelecto en acto y lo inteligido en acto son uno" (Tomás de Aquino, In duodecim libros Metaphysicorum Aristotelis expositio, 1950, XII, 1. I.11, 2610).

El concepto, sea fruto de la simple aprehensión o del juicio, es el acto en el que se dice lo entendido en acto. Luego, la unidad alcanzada en el acto de entender se expresa en el concepto. El concepto es semejante a la cosa conocida gracias a la especie de la que surge. Otra vez, no estamos delante de dos 'cosas', sino de una 'cosa' (lo conocido) y un 'acto' (el concepto). Son, evidentemente, dos desde el punto de vista del ser. Pero, gracias a la cualidad compartida, desde el punto de vista del contenido cognoscitivo son uno, uno en la cualidad.

Ahora bien, ¿son idénticos o son semejantes? Estrictamente hablando, son sólo semejantes. Pero, ¿qué es ser semejantes? Es, justamente, ser uno según la cualidad. Luego, desde el punto de vista noético, la semejanza implica unidad: un solo contenido cognoscitivo está presente en la cosa y el concepto.

La objeción de Roland-Gosselin no tiene, pues, asidero en este sentido. La insistencia de Maritain por hacer del concepto y la cosa 'idénticos' en el contenido esencial no hace más que explicitar en términos más fácilmente inteligibles (según su uso) la 'semejanza' que une al fruto del acto de conocer y a la cosa conocida.

\section{Si el concepto puede ser llamado signo}

Pasando a la segunda pregunta, que envuelve la segunda objeción de Roland-Gosselin, tenemos que dilucidar si el concepto -semejante a la cosa conocida- puede ser llamado signo o no.

Aquí es donde aparece con fuerza la figura de Juan de Santo Tomás. No ha sido él el primero en considerar que el concepto fuera un signo. Ockham ya lo había hecho previamente, aunque desde una perspectiva totalmente distinta 
a la de la metafísica clásica [cf. (Guillermo de Ockham, 1974, I, 12); (Panaccio, 1999, págs. 253-276)]. Pero sí ha sido él quien, en la escuela tomista, de manera más sólida y convincente ha expuesto la teoría del signo formal. ¿De qué se trata esta teoría?

Un signo es, según Juan de Santo Tomás, una entidad ordenada a otra cosa (lo designado) que manifiesta esa cosa a una facultad. Es de por sí representativo, pero no basta esto; su medida es lo significado: si no es adecuado para manifestar otra cosa a una facultad, no puede ser signo. Para que sea signo, además, es necesario que sea más conocido, inferior y desemejante a lo significado. Una señal de tránsito, para poner un ejemplo, es una entidad ordenada a otra cosa, como una curva. La misma señal manifiesta la curva a las facultades visiva e intelectiva del hombre. Es representativa de la curva si es adecuada para manifestarla; si la curva fuera hacia la izquierda, y la señal indicara que es hacia la derecha, aunque conservaría su carácter de representatividad, ese carácter no sería medido por la curva misma, y la señal de tránsito no sería un signo de esta curva. Además, la señal es más fácilmente conocida que la curva misma: la hace presente toda entera en vez de tener que recorrerla paso a paso; es inferior a la curva, puesto que una es la realidad, la otra simplemente la designa; y es desemejante a ella, puesto que son diversas en su ser: una es un dibujo, la otra, un camino. Cf. (Juan de Santo Tomás, 1930, II, q.XXI, a.6, Appendix).

El concepto es un signo según Juan de Santo Tomás. Por lo tanto, estas características se encuentran en él. Efectivamente, está ordenado a una cosa diversa y la manifiesta a la inteligencia; representa esta cosa por guardar una relación de semejanza con ella, que llega a sus características esenciales. La hace presente a la inteligencia y es diverso en su ser.

La característica de la noción de signo que el concepto no cumple es ser más fácilmente conocido que la cosa misma. En esto reside, precisamente, el hecho de que sea un signo 'formal':

Santo Tomás llama 'verbo' al instrumento por el que la inteligencia conoce algo, no como medio conocido -que es instrumento y medio externo- sino como medio interno, en el que la inteligencia entiende dentro de sí, y ésta es su índole de ser signo formal (Juan de Santo Tomás, Ars Logica seu De forma et materia ratiocinandi, II, q. XXII, q. 2). ${ }^{3}$

El signo formal, por lo tanto, hace conocer aquello que designa antes de darse a conocer a sí mismo en su calidad de signo. El concepto de agua nos hace conocer el agua manifestándola. En un solo acto conocemos el signo y el significado: el concepto de agua nos lleva directamente al agua, siendo un signo

\footnotetext{
3 "[...] D. Thomas vocat verbum instrumentum, quo intellectus aliquid cognoscit, non tamquam medium cognitum, quod est instrumentum et medium externum, sed ut medium internum, in quo intellectus intelligit intra se, et hoc est esse signum formale".
} 


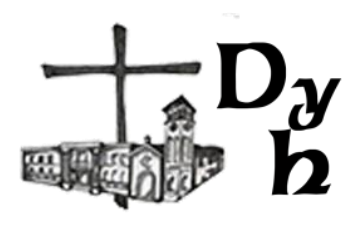

que no se manifiesta él mismo, sino perfectamente la realidad significada. Cf. (Juan de Santo Tomás, II, q. XXII, a. 2).

Ahora bien, de alguna manera tiene que ser conocido previamente. Si no, toda su realidad de signo se vería desdibujada. Juan de Santo Tomás entiende que, muy probablemente, el signo formal y su opuesto, el signo instrumental, son dos especies del mismo género, puesto que se dicen signo unívocamente:

En el parecer de santo Tomás, lo más probable es que el signo formal sea verdadera y propiamente signo, incluso unívocamente con el instrumental, si bien en el modo de significar difieran mucho (Juan de Santo Tomás, II, q. XXII, a.1). ${ }^{4}$

Luego, alguna prioridad en el conocimiento debe tener. Nuestro autor, consciente de esta situación, alega:

Para salvar la propiedad de signo, basta salvar que sea preconocido, lo cual se encuentra en el signo formal, no porque sea preconocido como objeto, sino como razón [ratio] y forma (por la que el objeto se vuelve conocido dentro de la potencia) y así es preconocido formalmente [formaliter], no denominativamente [denominative] ni como cosa conocida (Juan de Santo Tomás, II, q. XXII, a. 1). ${ }^{5}$

Así pues, lo que queda por esclarecer es qué debemos entender por una 'precognición' formal.

A nuestro entender, se trata de dos tipos de consideración del concepto: en sí mismo o en cuanto semejanza de la cosa conocida. En sí mismo es inteligido sólo por reflexión sobre el propio conocer, o sea, cuando se hace de él una cosa conocida. En cuanto semejanza, es inteligido formalmente en la intelección directa, lo cual quiere decir que se lo ve según el contenido inteligible de la cosa inteligida que en él se manifiesta; pero lo conocido propiamente hablando no es el concepto, sino la cosa [cf. (Maritain, Distinguer pour unir ou Les degrés du savoir, 1983, págs. 965-966)]. Por esta razón, en cuanto preconocido formaliter, se le podría aplicar la noción de 'signo'.

Es verdad que la distinción entre 'formalmente preconocido' o conocido en cuanto razón formal y 'denominativamente preconocido' o conocido en cuanto ente resulta un tanto difícil de aceptar, pero ilustra bastante bien la situación en la que se halla el concepto. La objeción de Roland-Gosselin es certera al señalar que no se puede denominar 'signo de otra cosa' a lo que se ha llamado 'idéntico a otra cosa'. El desdoblamiento entre 'ser idéntico' y 'ser signo' parecería ir contra el principio de no contradicción. Esto sería así si fuera al mismo tiempo y bajo el mismo respecto. Justamente, el problema aquí es que

\footnotetext{
4 "In sententia S. Thomae probabilius est signum formale esse vere et proprie signum, atque adeo univoce cum instrumentali, licet in modo significandi valde differant".

5 "Ex quo fit, quod ad salvandam proprietatem signi, sufficit salvare, quod sit praecognitum, quod in signo formali reperitur, non quia sit praecognitum ut obiectum, sed ut ratio et forma, qua obiectum redditur cognitum intra potentia, et sic est praecognitum formaliter, non denominative et ut res cognita".
} 
no es bajo el mismo respecto. En cuanto al contenido cognoscitivo hay semejanza, luego, conocer lo uno es conocer lo otro. En cuanto al ser, hay dualidad, luego uno me lleva (sin manifestarse en su ser) al otro.

Mantendremos, sin embargo, ciertas reservas sobre lo que acabamos de decir según el sentir de Juan de Santo Tomás y J. Maritain. Lo que los textos parecen expresar es que conozco la cosa a través de los conceptos, o, con más precisión, en los conceptos. De allí el problema de buscar un modo de justificar que hay una precognición del concepto que lleve a conocer la cosa. La precognición formaliter aparece como una solución que puede fundamentarse bien y sonar sensata.

Sin embargo, para ser justos, los conceptos no nos llevan a conocer la realidad como algo desconocido, ellos son el fruto de haberla conocido [cf. (Canals Vidal, Sobre la esencia del conocimiento, 1987, pág. 697)]. Luego, su calidad de signo es en cuanto que en ellos el intelecto manifiesta en su interior lo conocido [cf. (Tomás de Aquino, 1965, q. 9, a. 5, c.)]. Porque conozco algo formo un concepto que me reenvía naturalmente a ese algo del cual, en cuanto a su razón esencial, depende enteramente. Lo conocido, como es evidente, se dice denominative de la cosa, formaliter de la razón que aúna a la cosa y al concepto.

¿Qué lugar quedaría a la precognición formaliter? Resultaría, a nuestro parecer, una 'cognición' formaliter. No hay razón para establecer dicha razón de precognición que haría del concepto un 'signo'. Ahora bien, ¿esto anularía toda la teoría? No nos parece que sea así en primera instancia. Consideramos que vale la pena ahondar algo más en las preguntas que guían la investigación para retomar convenientemente este tema.

\section{Si la teoría del signo formal tiene sustento en los textos de santo Tomás}

Juan de Santo Tomás repetidas veces hace alusión al Aquinate para elaborar su propia enseñanza. En este apartado intentaremos ver si la teoría del signo formal puede, justamente, tomar sus principios de los escritos de santo Tomás. Nuestro objetivo no es constatar su fidelidad como intérprete según el sentir de É. Gilson (Le Philosophe et la Théologie, 1960, págs. 224-226), porque bien válida podría ser su elaboración sin referencia alguna a santo Tomás. Intentaremos, en cambio, resolver la objeción de Roland-Gosselin: la teoría del signo formal no parece seguirse de los textos de santo Tomás.

Hay pocos pasajes del Aquinate directamente relevantes en el asunto que nos concierne. El primero que cabría mencionar es un fragmento del Comentario a las Sentencias: 
En la cosa fuera del alma hay algo que responde a la concepción del alma, como el significado [responde] al signo (Scriptum super libros Sententiarum, I, d. 2, q. 1, a. 3, c.). ${ }^{6}$

Este texto no permite concluir que el concepto sea un signo, sino que la relación que tiene con la cosa es semejante a la que tiene el signo con el significado: en ambos casos hay un respecto que responde a su contenido cognoscitivo. Queda establecida en esta cita una analogía de proporcionalidad, es decir, una igualdad de proporciones: así como el significado responde al signo, así la cosa fuera del intelecto responde al concepto.

En las Cuestiones acerca de la verdad encontramos otros textos que pueden aclarar aún más esta situación:

Propiamente hablando, sólo se puede llamar 'signo' a algo desde lo cual se llega al conocimiento de otra cosa como si se discurriera [...]. Pero en general [communiter], podemos llamar 'signo' a cualquier cosa conocida en la que [in quo] se conoce otra, $y$, según esto, la forma inteligible se puede llamar 'signo de la cosa' que se conoce a través de ella (Quaestiones disputatae de Veritate, 1972-1976, q.9, a.4, ad 4m.). ${ }^{7}$

En este pasaje conviene señalar dos temas. El primero es la distinción de dos modos de llamar a algo 'signo': propiamente o en general. Podríamos decir 'signo en sentido estricto' y 'signo en sentido amplio'. Estrictamente hablando, se llama 'signo' a aquello que nos lleva a conocer otra cosa como si se discurriera, esto es, pasando explícitamente de una cosa a otra. Esto es lo que Juan de Santo Tomás llama signo instrumental. Así, el humo es signo instrumental del fuego y la voz articulada es signo instrumental de los conceptos de la mente. En sentido amplio, 'signo' es todo aquello en lo que se conoce otra cosa. En este segundo caso, no es necesario un conocimiento explícito del medio que nos lleva a conocer otra cosa distinta de él. De esta manera, 'signo' se puede entender de dos modos: estrictamente y ampliamente, denotando una relación, nuevamente, analógica entre ellos.

Asimismo, este texto pone en evidencia la propiedad analogada entre ambos modos de comprender el 'signo': algo se llama 'signo' si en él se conoce otra cosa. In quo, ésta es la expresión que usa santo Tomás para explicitar lo común entre los signos estricta y ampliamente tomados. Mientras que el texto del Comentario a las Sentencias nos llevaba a pensar que lo común entre el concepto y el signo era que en ambos casos algo responde a ellos, el presente pasaje nos hace ver que la forma inteligible y el signo (instrumental) pueden

\footnotetext{
6 "[...] in re extra animam est aliquid quod respondet conceptioni animae, sicut significatum signo".

7 "Ad quartum dicendum quod signum proprie loquendo non potest dici nisi aliquid ex quo deveniatur in cognitionem alterius quasi discurrendo [...]. Sed communiter possumus signum dicere quodcumque notum in quo aliquid cognoscatur; et secundum hoc forma intelligibilis potest dici signum rei quae per ipsam cognoscitur [...]".
} 
pensarse como medios de conocimiento porque ambos son en lo cual [in quo] algo es conocido.

En el Comentario al Evangelio de san Juan, santo Tomás dice que el concepto es aquello en lo que [in quo], no por lo que [quo], el intelecto intelige (cf. I, I.1, 25). De esta manera, la noción en sentido amplio de 'signo' y el concepto quedan vinculados.

Pero, ¿qué significa que el concepto sea un medio in quo? A nuestro entender, la expresión intenta hacer ver que en el concepto se da una doble valencia: por un lado, es lo entendido de la cosa expresado interiormente; por otro, por su universalidad y abstracción permite a la mente referirse a la realidad. Las cosas materiales son, de hecho, inteligidas no directamente, sino por cierta reflexión [cf. (Tomás de Aquino, Quaestiones disputatae de Anima, 1996, a.20 ad s.c. 1m.)]. Esto significa que, en primer lugar, entendemos inmaterial y universalmente lo que en la realidad se da material y particularmente. Luego, en eso entendido al modo del intelecto, por la sinergia entre el intelecto, la cogitativa y la imaginación, podemos contemplar lo material y concreto en sus razones universales, lo cual se manifiesta en los pronombres y atribuciones que hacen concretos a los nombres de por sí, justamente, universales. Por un lado, entonces, el concepto es lo inteligido; por otro, es por lo que se refiere a lo inteligido. La fórmula que parece resumir esta situación es decir que el concepto es en lo que se intelige algo concreto, como la perfección alcanzada en la operación.

Siendo, pues, un medio in quo del entender, el concepto puede ser llamado 'signo', pero en sentido amplio. De hecho, para ser un 'signo instrumental', debería pasarse del concepto a la cosa o estado de cosas como si se discurriera. Deberíamos, pues, conocer el concepto en cuanto cosa para llegar a lo significado por él en cuanto cosa, como se pasa de la señal de tránsito a la curva significada. Ahora bien, eso no sucede, salvo que hagamos del concepto nuestro objeto de atención. Los conceptos sólo expresan otra cosa, como también lo hacen en el ámbito sensible los recuerdos y las imágenes ${ }^{8}$. Son, por ello mismo, 'signos', pero en sentido amplio.

En otro pasaje de las Cuestiones acerca de la verdad, santo Tomás se ocupa del poder de significación de las palabras. Llamamos 'palabra' [verbum], en primer lugar, a la proferida exteriormente, a la voz articulada y significativa.

\footnotetext{
${ }^{8}$ Hay autores que no reconocen que los recuerdos o las imágenes sean signos formales: cf. Moya (2012), pág. 161-166 y pág. 166, n. 329. A nuestro entender sí lo son. Es más: son la razón por la que los animales somos capaces de interpretar e instituir todo signo instrumental. La diferencia entre el hombre y el animal no está en moverse o no por signos: mi perro comprende lo que le mando e incluso algunos de mis estados de ánimo, así como me hace entender por ciertas señales sus deseos. La diferencia radica en comprender el signo ut signum, es decir, en teorizar la relación de significación, algo que, hasta donde alcanza mi conocimiento, no se verifica en las otras especies animales fuera del hombre.
} 
Ahora bien, su significado es el concepto, el cual, en cuanto que en sí mismo expresa y manifiesta interiormente lo entendido, puede llamarse también por analogía verbum. La relación entre el verbum interior (o concepto) y el verbum exterior (o palabra proferida) puede entenderse del siguiente modo:

El verbo interior tiene antes razón de significación y manifestación que el verbo exterior, porque el verbo exterior se instituye para significar solamente a través del verbo interior (Tomás de Aquino, Quaestiones disputatae de Veritate, 19721976, q.4, a.1, ad 7m.). ${ }^{9}$

La palabra proferida es un signo instituido para significar algo. 'El tren está llegando' es una proposición que, pronunciada, se refiere a un estado de cosas. Ahora bien, el modo en el que las palabras articuladas dicen relación a las cosas es por medio de los conceptos. Las palabras significan directamente los conceptos, y los conceptos son semejanzas de las cosas [cf. (Aristóteles, Sobre la Interpretación, 1995, 16a 1-8); (Tomás de Aquino, Expositio libri Peryermeneias, 1989, 1. 2, 92-100)]. De esta manera las proposiciones acaban en las cosas mismas.

Ahora bien, santo Tomás afirma que al verbum interior antes le cabe la razón de manifestación y significación que al verbum exterior. Esto es así, según sus palabras, porque el concepto es la fuente desde la cual se instituye la palabra proferida con poder manifestativo y significativo. La palabra existe para referirse a otra cosa distinta de ella misma. En este sentido, no cabe duda, el concepto (y los frutos de la memoria y de la imaginación) existe igualmente para referirse a cosas distintas de él mismo. Porque existe lo segundo, existe lo primero. De allí que la razón de significación corresponda más al concepto que a la misma palabra.

La situación que acabamos de describir nos permitiría incluso vislumbrar un orden en los signos; sin embargo, estudiaremos esta situación en el próximo apartado. Quede establecido, sin embargo, que Roland-Gosselin carece de razón en esta objeción. Aunque santo Tomás no haya elaborado la teoría del signo formal, hay algunos indicios y elementos en sus textos que la sustentan.

\section{Conclusión}

Las objeciones de Roland-Gosselin han sido la ocasión de volver a pensar la teoría del signo formal. En particular, podemos decir que hay, al menos, dos temas importantes a estudiar. Uno es si el concepto es medio para conocer o bien nace del conocimiento ya formado. En este último caso, cabe decir que el concepto procede del conocimiento alcanzado como su fruto, $y$, al mismo tiempo, dirige la mente, por la imbricación con las potencias sensitivas, hacia aquello concreto de lo cual sus razones esenciales fueron abstraídas. Se trata,

\footnotetext{
9 "[...] verbum interius per prius habet rationem significationis et manifestationis quam verbum exterius quia verbum exterius non instituitur ad significandum nisi per interius verbum".
} 
pues, de un fruto y de un medio, de acuerdo al punto de vista que se tome, pero nunca de algo desconocido en su contenido noético. Es decir, es conocido ut ratio, es desconocido ut res.

Otro tema es la relación de analogía entre el signo formal y el instrumental, algo que Juan de Santo Tomás no ha considerado. Podemos llamar 'signo' al concepto porque lleva al intelecto a lo concreto desde sus razones universales. Sin embargo, no parece en modo alguno comportarse como el resto de los signos (instrumentales), puesto que habitualmente un signo lleva al significado como si se discurriera, lo cual no sucede con los signos formales. De allí que la relación entre uno y otro no parece ser de univocidad, sino de analogía.

Estos temas tienen que ser tratados en la siguiente parte de este estudio, al responder la última objeción de Roland-Gosselin. En razón de la extensión, conviene dejar esto para otra oportunidad. Allí también tendremos que afrontar algunos desacuerdos de fondo sobre la teoría del signo formal, que enriquecerán nuestra visión de conjunto.

\section{Bibliografía}

Aristóteles. (1995). Sobre la Interpretación. En Aristóteles, Tratados de Lógica (Órganon) (págs. 35-81). Madrid: Gredos.

Aristóteles. (2000). Metafísica. Madrid: Gredos.

Bacigalupe, D. J. (2014). Las Representaciones Mentales en Santo Tomás de Aquino: Un estudio a partir del debate contemporáneo. Roma: EDUSC.

Canals Vidal, F. (1987). Sobre la esencia del conocimiento. Barcelona: PPU.

Canals Vidal, F. (1989). La naturaleza de la Actividad Intelectual. El Pensamiento como lenguaje mental. Angelicum(66), 91-107.

Contat, A. (2012). Esse, essentia, ordo. Verso una metafisica della partecipazione operativa. Espíritu(143), 9-71.

Delly, J. (2008). How to Go Nowhere with Language: Remaks on John O'Callaghan, thomist, realism and the linguistic turn. American Catholic Philosophical Quarterly(82), 337-359.

Gilson, É. (1960). Le Philosophe et la Théologie. París: Librarie Arthème Fayard.

Guillermo de Ockham, F. M. (1974). Summa Logicae. New York: Editiones Instituti Franciscani Universitatis S. Bonaventurae.

Hayen, A. (1939). Intentionnalité de l'être et Métaphysique de la participation. Revue néo-scolastique de philosophie(63), 385-410. 
Juan de Santo Tomás, O. P. (1930). Ars Logica seu De forma et materia ratiocinandi. Marietti, Taurini.

Llano, A. (1999). El Enigma de la Representación. Madrid: Síntesis.

Maritain, J. (1983). Distinguer pour unir ou Les degrés du savoir (Vol. Tomo V). Fribourg-París: Éditions Universitaires-Éditions Saint-Paul.

Maritain, J. (1984). Réflexions sur l'intlligence et sur sa vie propre (Vol. Tomo III). Fribourg-París: Éditions Universitaires-Éditions Saint-Paul.

Maritain, J. (1988). En J. Maritain, Quatre essais sur l'espirit dans sa condition charnelle (Vol. Tomo VII, págs. 51-280). Fibourg-París: Éditions Universitaires-Éditions Saint-Paul.

Moya, P. (2012). El Conocimiento: nuestro acceso al mundo. Santiago de Chile: Editorial Universitaria.

Osborne, T. (2010). The concept as a formal sign. Semiotica(179), 1-21.

Panaccio, C. (1999). Le discours intérieur de Platon à Guillaume d'Ockham. París: Editions du Seuil.

Roland-Gosselin, M. D. (1925). Métaphysique-Théorie de la connaissance et systèmes généraux. Revue des Sciences Philosophiques et Théologiques(14), 200-216.

Tomás de Aquino, S. (1888-1906). Summa Theologiae (Edición Leonina ed., Vols. Tomo IV-XII). Romae: Typographia Polyglotta S. C. de Propaganda Fide.

Tomás de Aquino, S. (1929-1947). Scriptum super libros Sententiarum (Vols. Tomos I-IV). Parisiis: Lethielleux.

Tomás de Aquino, S. (1950). In duodecim libros Metaphysicorum Aristotelis expositio. Taurini-Romae: Marietti.

Tomás de Aquino, S. (1965). Quaestiones disputatae de Potentia. En S. Tomás de Aquino, Quaestiones disputatae II. Taurini-Romae: Marietti.

Tomás de Aquino, S. (1972). Super Evangelium s. Ioannis lectura. Taurini-Romae: Marietti.

Tomás de Aquino, S. (1972-1976). Quaestiones disputatae de Veritate (Vol. Tomo XXII). Roma: Editio Leonina/1-3 Editori di san Tommaso.

Tomás de Aquino, S. (1989). Expositio libri Peryermeneias (Vol. Tomo I*). RomaeParis: Commissio Leonina-Vrin.

Tomás de Aquino, S. (1996). Quaestiones disputatae de Anima (Vol. Tomo XXIV). (E. Leonina, Ed.) Romae-Paris: Commissio Leonina-Éditions du Cerf. 